\title{
ANALISIS BIAYA PERBAIKAN DAN PERAWATAN GEDUNG SEKOLAH SWASTA $X$
}

\author{
Stefanus ${ }^{1}$ \\ ${ }^{1}$ Magister Teknik Sipil, Universitas Tarumanagara \\ Email: ssunarno1989@gmail.com
}

Masuk: 14-01-2020, revisi: 28-04-2020, diterima untuk diterbitkan: 01-05-2020

\begin{abstract}
ABSTRAK
Perencanaan perawatan dan perbaikan gedung sangat diperlukan untuk menjaga gedung tersebut agar dapat digunakan dengan baik untuk jangka waktu yang panjang. Perawatan dan perbaikan gedung pada umumnya dilakukan oleh manajemen gedung. Pada bangunan sekolah juga diperlukan peran manajemen gedung dalam melakukan perawatan saranan dan sarana bangunan gedung. Dengan sarana dan prasarana gedung sekolah yang baik dan terawat, akan membuat nilai dari sekolah itu tinggi. Penelitian ini dilakukan dengan mengumpulkan data sekunder dari seluruh biaya perbaikan dan perawatan bangunan gedung di lima lokasi sekolah swasta X dari tahun 2016 - 2018, serta nilai awal pembangunan gedung tersebut dan data diolah menggunakan Microsoft Excell. Dari data di dapat untuk nilai perbaikan dan perawatan total dari lima lokasi sekolah swasta $\mathrm{x}$ selama 3 tahun sebesar Rp. 12.107.423.758,-. Total nilai biaya tersebut didapat perawatan dan perbaikan Mechanical Electrical Plumbing (MEP) dan arsitektur, untuk perbaikan dan perawatan pondasi dan struktur sekolah swasta X tidak mengeluarkan biaya. Untuk biaya perawatan dan perbaikan MEP sebesar Rp. 5.048.736.655,- dan arsitektur sebesar Rp. 7.058.687.103,-. Besarnya nilai biaya perawatan dan perbaikan salah satunya dsebabkan karena tidak adanya prosedur untuk perbaikan sarana dan prasarana. Biaya perawatan dan perbaikan hanya dilakukan bila sarana dan prasarana sudah rusak dan tidak bisa dipakai, serta tidak adanya jadwal rutin perawatan. Salah satu yang harus dilakukan sekolah swasta $\mathrm{X}$ adalah dengan memperbaiki sistem perawatan yang dilakukan oleh manajemen gedung agar dapat mengurangi biaya perbaikan sarana dan tetap menjaga sarana dan prasarana dalam kondisi baik.
\end{abstract}

Kata Kunci: Analisis Biaya Bangunan Sekolah; Manajemen Gedung; Standar Operasional Prosedur (SOP) Manajemen Gedung

\begin{abstract}
Planning for building maintenance and repairs is necessary to maintain the building so that it can be used properly for a long period of time. Building maintenance and repairs are generally carried out by building management. In the school building also needed the role of building management in carrying out maintenance and building facilities. With the facilities and infrastructure of a good and well-maintained school building, it will make the value of the school high. This research was conducted by collecting secondary data from all costs of repair and maintenance of buildings in five X private school locations from 2016 - 2018, as well as the initial value of the building construction and data processed using Microsoft Excel. From the data obtained for total repair and maintenance value from five locations of private schools $x$ for 3 years amounting to Rp. 12,107,423,758. The total value of the costs obtained maintenance and repair of Mechanical Electrical Plumbing (MEP) and architecture, to repair and maintain the foundation and structure of private schools $X$ does not incur costs. For MEP maintenance and repair costs of $R p$. 5,048,736,655 and architecture Rp. 7,058,687,103. One of the high value of maintenance and repair costs is due to the absence of procedures for repairing facilities and infrastructure. Maintenance and repair costs are only carried out if the facilities and infrastructure are damaged and cannot be used, and there is no routine maintenance schedule. One of the things that must be done by private school $X$ is to improve the maintenance system carried out by building management so that it can reduce the cost of repairing facilities and keep the facilities and infrastructure in good condition.
\end{abstract}

Keywords: School Building Cost Analysis; Building Management; Building Management Standard Operating Procedure (SOP) 


\section{PENDAHULUAN}

\section{Latar Belakang}

Dalam pembangunan konstruksi dibutuhkan sebuah pengaturan dan pengendalian seluruh kegiatan proyek, atau yang disebut Manajemen Kontruksi. Pengaturan dan pengendalian tersebut dapat berupa hasil dari peranan seluruh konsultan, mulai dari merencanakan, mengarahkan, serta mengawasi kegiatan tersebut dari awal hingga selesai.

Menurut Neo (2014), tujuan dari Manajemen Konstruksi adalah mengatur pelaksanaan pembangunan hingga didapat hasil yang optimal. Untuk mendapatkan hasil yang optimal dibutuhkan pengawasan dari para pihak terkait (dalam hal ini adalah konsultan). Adapun manfaat dari manajemen konstruksi dapat dilihat dari aspek biaya, mutu, dan waktu. Salah satu konstruksi yang banyak ditemui adalah gedung bertingkat. Dalam pembangunan gedung juga dibutuhkan sistem manajemen yang baik, mengingat peruntukan gedung itu sendiri yang akan digunakan. Salah satunya adalah faktor waktu sangat penting bagi pemilik proyek, karena pemilik proyek mengharapkan keuntungan operasi dari bangunan tersebut.

Salah satu lingkup dari manajemen gedung adalah perawatan gedung. Perawatan gedung tersebut mencakup segi kebersihan, keamanan, dan kenyamanan. Dari segi kenyamanan gedung harus selalu dipastikan dalam keadaan terawat, sehingga meminimalisir kerusakan - kerusakan gedung yang akan terjadi. Sebagai Building Management (pengelola gedung) bertugas untuk mempertahankan kualitas gedung, mulai dari sistem mekanikal, elektrikal, sipil, elektronik, hingga pemipaan. Salah satu upaya untuk mencegah terjadinya kerusakan pada gedung adalah dengan cara memastikan seluruh komponen yang terdapat pada gedung berfungsi dengan baik.

Dari segi perawatan bangunan gedungnya perlu dilakukan perawatan yang lebih layak seperti warna dinding yang mulai pudar, plafon rusak dan toilet yang kurang terawat. Di dalam gedung tersebut terdapat ruangan alat - alat besar, seperti generator set (genset), ground dan roof tank, pompa - pompa, dan lain - lain.

Menurut Neo (2014), Manajemen perawatan gedung adalah usaha yang dilakukan mulai dari perencanaan sampai dengan pelaksanaan pekerjaan perawatan suatu gedung beserta fasilitas yang ada di dalamnya dengan tujuan untuk mendapatkan hasil seoptimal mungkin, dengan memperhatikan batasan-batasan waktu, biaya dan mutu.

Dalam dunia sekolah juga memerlukan perawatan gedung sekolah untuk menunjang kegiatan belajar mengajar di sekolah. Di sekolah terdapat ruangan untuk kegiatan belajar mengajar, lapangan olah raga, ruang serba guna (Aula) dan laboratoriun untuk menunjang kegiatan belajar mengajar yang perlu untuk dikelola agar tetap dalam kondisi baik dan layak untuk digunakan oleh siswa.

\section{Rumusan Masalah}

a. Apa saja yang sudah dilakukan oleh sekolah swasta $\mathrm{X}$ dalam perawatan sarana dan prasarana gedung sekolah?

b. Berapakah besar nilai biaya yang dikeluarkan untuk perawatan dan perbaikan bangunan gedung sekolah dan sarana prasarana di sekolah swasta X selama 3 tahun terakhir?

c. Apa saja peraturan dan ketentuan yang harus ditambahkan dalam menjalankan proses perawatan bangunan gedung serta sarana dan prasarana sekolah swasta $X$ ? 


\section{Tujuan Penelitian}

a. Mengetahui apa saja yang sudah dilakukan oleh manajemen gedung di sekolah swasta X.

b. Mengetahui dan menganalisis besarnya nilai yang sudah dikeluarkan oleh yayasan dari sekolah X.

c. Mempelajari beberapa contoh Standar Operasional Prosedur (SOP) Manajemen gedung dan Permen PUU N0. 24 tahun 2008 untuk memberikan masukan sebagai usulan untuk Standar Operasional Prosedur (SOP) kepada manajemen gedung yang sesuai dengan kebutuhan sekolah swasta X.

\section{METODE PENELITIAN}

Penelitian ini dilakukan dengan mengumpulkan data sekunder dari seluruh biaya perbaikan dan perawatan bangunan gedung di 5 (lima) lokasi sekolah swasta X dari tahun 2016 -2018 (3 tahun), serta nilai awal pembangunan gedung tersebut. Instrumen yang digunakan adalah dokumentasi data perbaikan dan perawatan gedung sekolah swasta X selama 3 tahun terakhir yang diolah menggunakan Microsoft Excel. Hasil dari pengolahan data pada Microsoft Excel berguna untuk mengetahui total biaya yang dikeluarkan yayasan sekolah swasta X selama 3 (tiga) tahun terakhir (2016-2018) di lima lokasi sekolah swasta X. Hasil pengolahan data di Microsoft Excel berguna untuk pengelompokan data perawatan dan perbaikan bangunan gedung di sekolah. Penelitian ini diharapkan dapat menghasilkan kebijakan-kebijakan untuk meningkatkan kualitas Building Management di sekolah swasta $\mathrm{X}$ atau sekolah-sekolah lainnya yang mempunyai manajemen perawatan bangunan gedung sekolah.

\section{HASIL DAN PEMBAHASAN}

Perawatan dan perbaikan di sekolah swasta $\mathrm{X}$ saat ini hanya dikerjakan apabila ada permintaan dari pihak sekolah terkait. Perawatan dan perbaikan sarana dan prasarana gedung sekolah seharusnya memiliki jadwal rutin agar sarana dan prasarana dapat difungsikan sesuai dengan kebutuhan dan memiliki usia yang panjang. Dari data yang diperoleh biaya perbaikan lebih besar dari pada biaya perawatannya. Dan biaya perbaikan dan perawatan saat ini tidak memiliki pola yang baik karena tidak adanya prosedur atau SOP dari manajemen gedung untuk perawatan maupun perbaikan sarana dan prasarana gedung. Pada Tabel 1 disajikan hasil dari analisis biaya perawatan dan perbaikan sekolah swasta $X$ selama kurun waktu 3 tahun terakhir dan pada gambar 1 juga terlampir grafik peningkatan dan penurunan dari biaya perbaikan dan perawatan di sekolah swasta X selama 3 tahun terakhir.

Tabel 1. Biaya Perbaikan dan Perawatan Sekolah swasta X di lima lokasi

Biaya Perawatan Dan perbaikan

20172018

$334,992,160$

$468,612,250$

$1,311,198,455$

$1,486,509,848$

$465,811,050$

$4,067,123,763$

2018

$472,166,11$

$794,495,400$

$1,492,078,055$

$1,243,423,250$

$770,352,900$

$\mathbf{4 , 7 7 2 , 5 1 5 , 7 1 5}$
Persentase Perawatan Dan perbaikan

$\begin{array}{cccc}2016 & \mathbf{2 0 1 7} & \mathbf{2 0 1 8} & \begin{array}{c}\mathbf{2 0 1 6 -} \\ \mathbf{2 0 1 8}\end{array} \\ 2.54 \% & 4.57 \% & 6.44 \% & 13.54 \%\end{array}$

$\begin{array}{llll}0.75 \% & \mathbf{0 . 7 2} \% & \mathbf{1 . 2 1} \% & \mathbf{2 . 6 8} \%\end{array}$

$\begin{array}{llll}4.56 \% & 6.06 \% & 6.89 \% & 17.50 \%\end{array}$

$\begin{array}{llll}2.67 \% & 2.93 \% & 2.45 \% & 8.04 \%\end{array}$

$\begin{array}{llll}\mathbf{0 . 5 7 \%} & 0.89 \% & 1.47 \% & 2.92 \%\end{array}$

$1,536,944,140$

$\mathbf{1 2 , 1 6 1 , 1 1 3 , 7 5 8}$

$\begin{array}{llll}1.68 \% & 2.06 \% & 2.41 \% & 6.15 \%\end{array}$ 


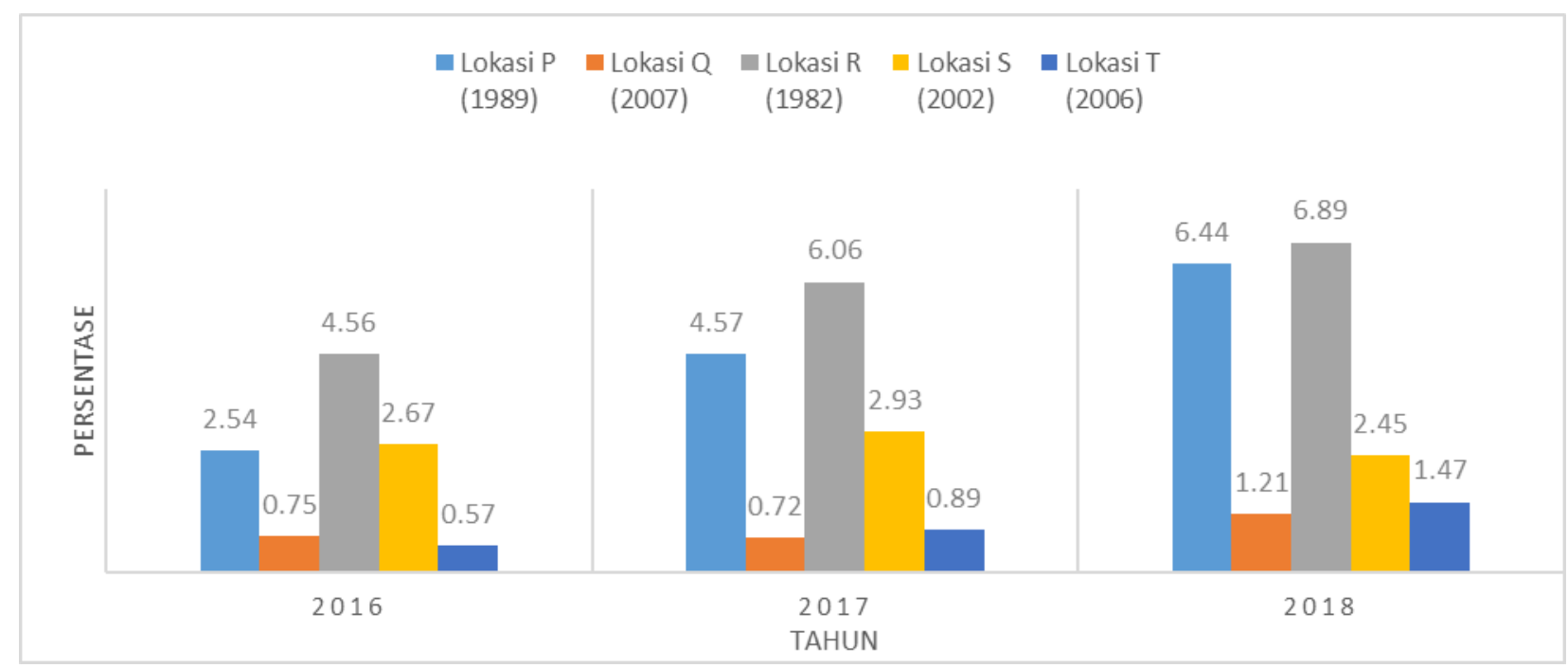

Gambar 1. Grafik biaya perbaikan dan perawatan sekolah swasta X di lima lokasi

Untuk biaya perbaikan total perawatan dan perbaikan adalah Rp. 12.107.323.758,- dengan rincian arsitektur Rp. 7.058.587.103 dan Mechanical Electrical Plumbing (MEP) Rp. 5.048.736.655,-. Untuk biaya perbaikan struktur dan pondasi selama tiga tahun terakhir tidak ada atau tidak ada anggaran yang berarti struktur dan pondasi masih sangat baik. Dari total biaya perawatan dan perbaikan untuk biaya perbaikan jauh lebih besar dari pada biaya perawatan baik untuk arsitektur maupun MEP. Dari data yang diperoleh, saat ini belum dilakukan sistem perawatan bangunan dengan baik. Sebagai contoh perawatan bangunan hanya dilakukan bila terjadi kerusakan pada bangunan yang lainnya, misalkan bangunan A mengalami kerusakan di panel akibat umur kabel yang sudah lebih dari 20 tahun, maka gedung lain pun baru akan melakukan perawatan untuk gedung tersebut..

Pada Tabel 1 di tunjukan untuk nilai untuk perbaikan dan perawatan terbesar ada di lokasi S dan terendah ada di lokasi P. Faktor yang mempengaruhi adalah luasan bangunan sekolah itu sendiri untuk S memiliki luas bangunan sebesar $36.137 \mathrm{~m}^{2}$ (luas tertinggi dari kelima lokasi), sedangkan untuk lokasi P memiliki luasan bangunan sebesar $2.523 \mathrm{~m}^{2}$ (Terendah dari kelima lokasi).

\section{KESIMPULAN DAN SARAN}

\section{Kesimpulan}

Untuk saat ini perawatan dan perbaikan gedung yang sudah dilakukan oleh sekolah swasta X adalah dengan melakukan perbaikan berdasarkan checklist dari para staf teknis (checklist hanya catatan dari hasil keliling staff ke area sekolah dan tidak ada form khusus). Perbaikan dan perawatan hanya dilakukan bila staff atau teknisi mengusulkan biaya perbaikan. Dan usul untuk perawatan dan perbaikan baru bisa dijalakan bila memang sarana atau prasarana yang diusulkan untuk dilakukan perbaikan memang sangat membutuhkan perbaikan, apabila sarana dan prasarana masih bisa dipakai sehingga ketika memang sarana dan prasarana rusak, membutuhkan biaya perbaikan yang jauh lebih mahal.

Perawatan bangunan gedung di sekolah swasta X saat ini tidak bisa dikatakan baik karena dari data yang didapat selama perawatan dan perbaikan yang dilakukan manajemen gedung lebih 
besar dilakukan untuk perbaikan. Salah satu penyebab tingginya biaya perbaikan karena tidak adanya SOP atau prosedur untuk perawatan bangunan gedung baik arsitek maupun MEP, oleh sebab itu memberikan saran konsep untuk pembuatan SOP yang bisa dijadikan acuan untuk pembuatan SOP yang baku dan disahkan untuk dijalankan oleh manajemen gedung. Total nilai perawatan dan perbaikan Rp. 12.107.423.758

Dari Mechanical Electrical Plumbing (MEP) diatas sekolah swasta X dengan lokasi di S memiliki nilai perbaikan terbesar yaitu 37,02 \%. Dari data tersebut nilai terbesar di dapat dari perbaikan AC sebesar Rp. 353.151.600,-. Untuk mengurangi nilai perbaikan dibutuhkan perawatan yang baik atau rutin. Untuk itu dibutuhkan SOP untuk setiap perawatan bangunan gedung dari sisi MEP maupun Arsitektural.

Dari kelima lokasi sekolah swasta X, biaya perbaikan dan perawatan terbesar adalah perbaikan AC. AC saat ini merupakan suatu kebutuhan yang harus ada di setiap kelas dan ruangan, tetapi untuk perawatan $\mathrm{AC}$ ini sendiri masih kurang dan hanya akan diperbaiki bila ada keluhan dari sekolah (keluhan AC mati atau panas). Perawatan AC dapat dilakukan dengan melakukan pengecekan rutin ampere AC, freon dan pengecekan unit dalam serta luar dari setiap unit AC. Untuk itu dibutuhkan suatu pedoman atau prosedur yang harus dimiliki manajemen gedung $\mathrm{X}$ dalam melakukan perawatan agar dapat meminimalkan biaya yang dikeluarkan untuk perbaikan AC.

Melihat dari prosedur PERMEN PUU No. 24 Tahun 2008 perawatan dan perbaikan gedung di sekolah swasta X saat ini belum sepenuhnya sudah dilaksanakan dengan baik itu dapat dilihat dari beberapa kategori yang tidak mengikuti prosedur. Bahkan saat ini di sekolah swasta X tidak ada SOP tertulis secara baku sebagai pedoman untuk pelaksanaan perawatan bangunan gedung dan elemen dari gedung tersebut.

\section{Saran}

Perlunya pembuatan SOP dalam melakukan perbaikan dan perawatan gedung di sekolah swasta $\mathrm{X}$, sehingga sekolah Swasta X dapat menekan biaya perbaikan sekolah dan memprediksi biaya perawatan gedung sekolah.

\section{REFERENSI}

Direktorat Jenderal Cipta Karya. (2008): Peraturan Menteri Pekerjaan Umum Nomor: 24/PRT/M/2008 tentang Pedoman Pemeliharaan dan Perawatan Bangunan Gedung, Indonesia - Departemen Pekerjaan Umum.

Direktorat Pembinaan Sekolah Menengah Atas Direktorat Jenderal Pendidikan Menengah Kementerian dan Kebudayaan. (2011). Paduan Teknis Perawatan Bangunan Sekolah.

Handayani, Anita. (2009): Pengembangan konsep Standar Operasional Prosedur Pada Proses Manajemen Pemeliharaan dan Perawatan Bangunan Gedung. Universitas Indonesia, Jakarta

Magee, PE, GH. (1988): Facilities Maintenance Management, R.S Mean Company Inc.

Peraturan Daearah Provinsi Daerah Khusis Ibukota Jakarta Nomer 7 Tahun 2010 tentang Bangunan Gedung.

Undang-Undang Republik Indonesia Nomer 2 Tahun 2017 tentang Jasa Konstruksi, 33-34 
Usman, Kristianto. (2009): “Kajian Manajemen Pemeliharaan Gedung (Building Maintenance) di Universitas Lampung”. Rekayasa, Jurnal Sipil dan Perencanaan, Vol. 13, Lampung.

Widiasanti, Irika \& Eka, Murtinugraha. (2016): "Kajian Pengelolaan Tentang Pemeliharaan dan Perawatan Gedung Perguruan Tinggi: Studi Kasus Universitas Negeri Jakarta". Jurnal Universitas Negeri Jakarta 